\title{
Correction to: Anti-tumor and anti-metastasis efficacy of E6201, a MEK1 inhibitor, in preclinical models of triple-negative breast cancer
}

\author{
Jangsoon Lee ${ }^{1,3} \cdot$ Bora Lim $^{1,3} \cdot$ Troy Pearson $^{1} \cdot$ Kuicheon Choi $^{1}$. Jon A. Fuson ${ }^{1}$. Chandra Bartholomeusz ${ }^{1,3}$. \\ Linda J. Paradiso ${ }^{2} \cdot$ Thomas Myers $^{2} \cdot$ Debu Tripathy $^{1} \cdot$ Naoto T. Ueno $^{1,3}$
}

Published online: 15 April 2019

(c) Springer Science+Business Media, LLC, part of Springer Nature 2019

\section{Correction to: Breast Cancer Research and Treatment https://doi.org/10.1007/s10549-019-05166-3}

Unfortunately in the original publication of the article, the author's funding support has been mentioned incorrectly. The correct funding statement should read as "This work was supported by the Morgan Welch Inflammatory Breast Cancer Research Program, the State of Texas Rare and Aggressive Breast Cancer Research Program, MD Anderson's Cancer Center Support Grant (P30CA016672, used the Characterized Cell Line Core Facility and Flow Cytometry and Cellular Imaging Facility), and Spirita Oncology, LLC."

The first affiliations was incorrect in the original article. The correct information is given below.
The original article can be found online at https://doi.org/10.1007/ s10549-019-05166-3.

Naoto T. Ueno

nueno@mdanderson.org

1 Section of Translational Breast Cancer Research, Department of Breast Medical Oncology, The University of Texas MD Anderson Cancer Center, Houston, TX 77030-4009, USA

2 Spirita Oncology, LLC, Natick, MA, USA

3 Morgan Welch Inflammatory Breast Cancer Research Program and Clinic, Department of Breast Medical Oncology, The University of Texas MD Anderson Cancer Center, Unit 1354, 1515 Holcombe Boulevard, Houston, TX 77030-4009, USA
Publisher's Note Springer Nature remains neutral with regard to jurisdictional claims in published maps and institutional affiliations. 